\title{
CAMEL SPIDER (SOLIFUGAE) USE OF PRAIRIE DOG COLONIES
}

\author{
B.D. Duval ${ }^{1}$ and W.G. Whitford ${ }^{2,3}$
}

\begin{abstract}
Solifugids (camel spiders) are widespread throughout arid regions of western North America and are thought to be important in structuring desert arthropod communities. Despite the ubiquity of camel spiders, little is known about their ecology. Black-tailed prairie dogs (Cynomys ludovicianus) are also widespread in western North America and are important ecosystem engineers, but they have been reduced in extent because of human activity. Here we report significantly greater numbers of camel spiders on black-tailed prairie dog colonies in southern New Mexico. The difference in vegetation structure created by prairie dog activity is likely the reason for the increased prevalence of camel spiders on colonies. Because camel spiders are important predators and prey, the observation that colonies support higher numbers of these animals provides a mechanism explaining differences in arthropod communities on and off colonies and explaining the preferential foraging behavior of vertebrates associated with prairie dog colonies.
\end{abstract}

Key words: black-tailed prairie dogs, Chihuahuan desert, ecosystem engineering, Solifugae, grassland ecology.

Camel spiders (Arachnida, Solifugae) are widely distributed in desert regions of western North America. These arachnids are voracious predators that consume arthropods, lizards, and even small mammals (Muma 1966a, Punzo 1998). Camel spiders are also prey for birds and other arthropods (Polis and McCormick 1986, York et al. 2002). Though camel spiders are likely important in desert systems as both predators and prey, data regarding camel spider ecology are scant, and factors regulating their abundance are not well understood.

Camel spiders appear to prefer areas with specific vegetation and soil characteristics, but no generalizations about their habitat have been identified (Brookhart 1972, Punzo 1998). In the Chihuahuan desert of western Texas and New Mexico, camel spiders prefer arroyos with open sandy soils and desert grasslands (Muma 1979, Punzo 1998). Arroyos and desert grasslands seem to be disparate habitat types, but grasslands in southern New Mexico are characterized by open patches of bare ground similar to arroyo sites (Duval et al. 2005).

Black-tailed prairie dogs (Cynomys ludovicianus) are ecosystem engineers, organisms that modify biotic and abiotic components of their environments (Jones et al. 1994, 1997). Blacktailed prairie dogs change soil processes, provide habitat for other vertebrates, and increase arthropod diversity (Whicker and Detling 1988,
Weltzin et al. 1997, Desmond et al. 2000, Bangert and Slobodchikoff 2006). Most importantly for ground-dwelling predators like camel spiders, black-tailed prairie dogs increase the percent cover of bare ground on their colonies by decreasing vegetation height and cover and by altering plant community structure (Agnew et al. 1986). Considerable interest has been given to the role of prairie dogs in grasslands, because they have been drastically reduced due to human activity such as shooting, poisoning, and introduction of plague (Stapp 1998, Vermeire et al. 2004). Information about camel spider presence or absence from prairie dog colonies adds to what we know about how prairie dogs influence arthropods at large, especially if colonies represent favorable habitat for camel spiders.

Because camel spiders occupy a middle trophic niche in areas they inhabit, they can influence top-down (predatory) and bottomup (prey) processes in desert systems. If camel spider abundance is higher on black-tailed prairie dog colonies compared to undisturbed grassland, prairie dogs could indirectly alter arthropod communities by enhancing predation pressure on the arthropods (from camel spiders) and increasing prey availability for organisms like burrowing owls that feed on camel spiders. Determining the relationship between camel spiders and black-tailed prairie

${ }^{1}$ Department of Biological Sciences, Northern Arizona University, Flagstaff, AZ 86011. E-mail: benjamin.duval@nau.edu

${ }^{2}$ USDA-ARS Jornada Experimental Range, New Mexico State University, Box 30003, Campus Box 4901, Las Cruces, NM 88003.

${ }^{3}$ Department of Fishery and Wildlife Sciences, New Mexico State University, Las Cruces, NM 88003. 

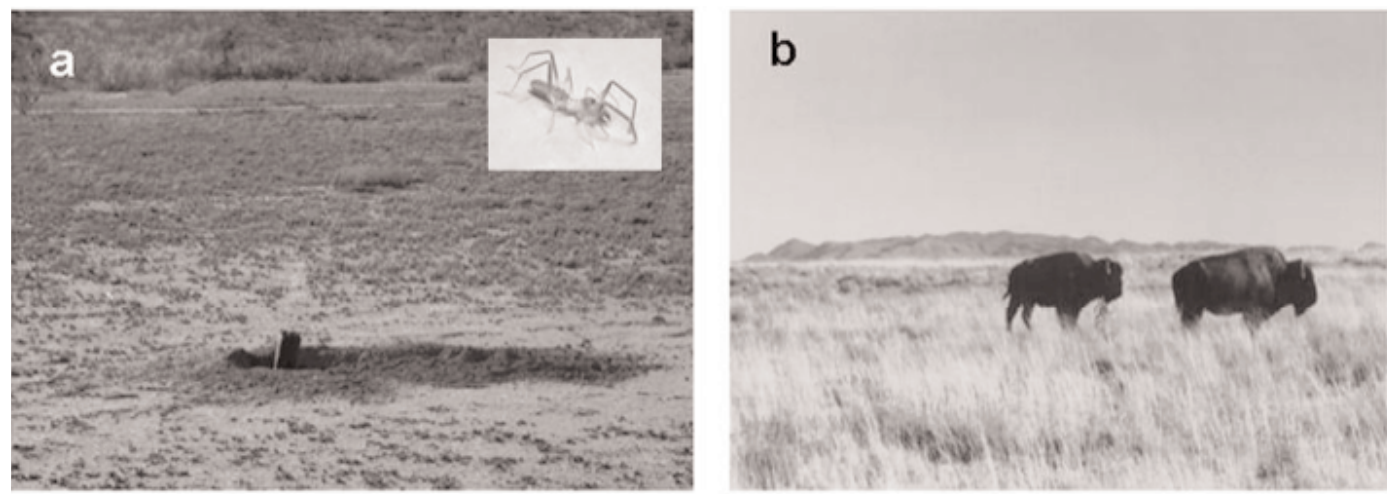

Fig. 1. Prairie dog colony at the Armendaris Ranch, New Mexico: A, prairie dog colony; A-inset, camel spider; and B, adjacent $(\sim 100 \mathrm{~m}$ away) grassland undisturbed by prairie dog activity.

dogs will provide additional information about the ecological role of prairie dog colonies in grasslands and will disseminate basic ecological information on camel spiders.

We collected camel spiders on and off of prairie dog colonies at the Armendaris Ranch, about $40 \mathrm{~km}$ northeast of Truth or Consequences, New Mexico. The ranch encompasses approximately 146,000 ha of intact Chihuahuan desert grassland and hosts burrograss (Scleropogon brevifolius), alkali sacaton (Sporobolus airoides), and tobosa (Hilaria mutica) grasses, interspersed with opuntia (Opuntia spp.), honey mesquite (Prosopis glandulosa), and ephedra (Ephedra torreyana) shrubs (DickPeddie 1993). Black-tailed prairie dogs were reintroduced to the Armendaris Ranch in 1994. Prairie dogs were introduced in low-lying, sandy-loam-soil habitats characteristic of areas in which they historically resided (Hoogland 1995).

We collected camel spiders on 5 black-tailed prairie dog colonies and in 5 corresponding adjacent grassland patches $(n=5$ sites per "treatment" of colony or grassland). We installed 5 pitfalls on each colony: 1 in the center and 1 placed $100 \mathrm{~m}$ from the edge of colony on each of 4 randomly generated compass bearings. This was deemed a sufficient number of traps based on experimental studies of trapping efficiency in the Chihuahuan desert (Whitford 1975). Collections were made during four 6week periods between summer 2003 and summer 2004 (Greenslade 1964, Topping and Sunderland 1992). Pitfall traps were emptied weekly during each 6 -week sampling period. Results are reported only for the 12 dates that camel spiders were detected in the traps. We considered colonies as replicate plots and report abundances as the mean number of camel spiders collected per sampling date within each sampling season for either the colony or grassland plots.

We measured the vegetation structure of colonies and adjacent grassland using 100-m transects along the pitfall grid. We estimated percent basal cover of vegetation and bare ground by overlaying a $0.5-\mathrm{m}^{2}$ frame with 10 $\times 10$-cm squares every $10 \mathrm{~m}$ along the transects (Daubenmire 1968). We randomized height measurements within each frame by recording the height of the first 3 plants within the center row of the frame grid. Height and percent cover of bare or vegetated ground are reported as mean height in centimeters or mean percent cover. Statistical analyses were performed with JMP v.5.1 and SAS.

The vegetation differences between prairie dog colonies and grassland are well documented and extreme (Fig. 1). The mean vegetation height on black-tailed prairie dog colonies was significantly shorter than on adjacent grassland patches $\left(4.70 \mathrm{~cm}\left[s_{\bar{x}}=0.36\right]\right.$ vs. 9.59 $\mathrm{cm}\left[s_{\bar{x}}=0.74\right]$; Kruskal-Wallis test: $\chi^{2}=$ 35.19 , $\mathrm{df}=1, P<0.001)$. The vegetation cover was more than 3 times greater in grassland than on the colony $\left(10.66 \%\left[s_{\bar{x}}=0.87\right]\right.$ vs. $3.32 \%\left[s_{\bar{x}}=0.29\right] ; \chi^{2}=33.07, \mathrm{df}=1, P<$ 0.001 ). Colonies supported a higher percentage of bare ground than grassland plots as well (96.7\% vs. $89.3 \%$; one-way ANOVA: $F_{1,8}=$ 5.32, $P<0.01)$. Vegetation height and cover were positively correlated (Spearman's rank correlation: $\left.r_{\mathrm{s}}=0.71, P<0.001\right)$. 


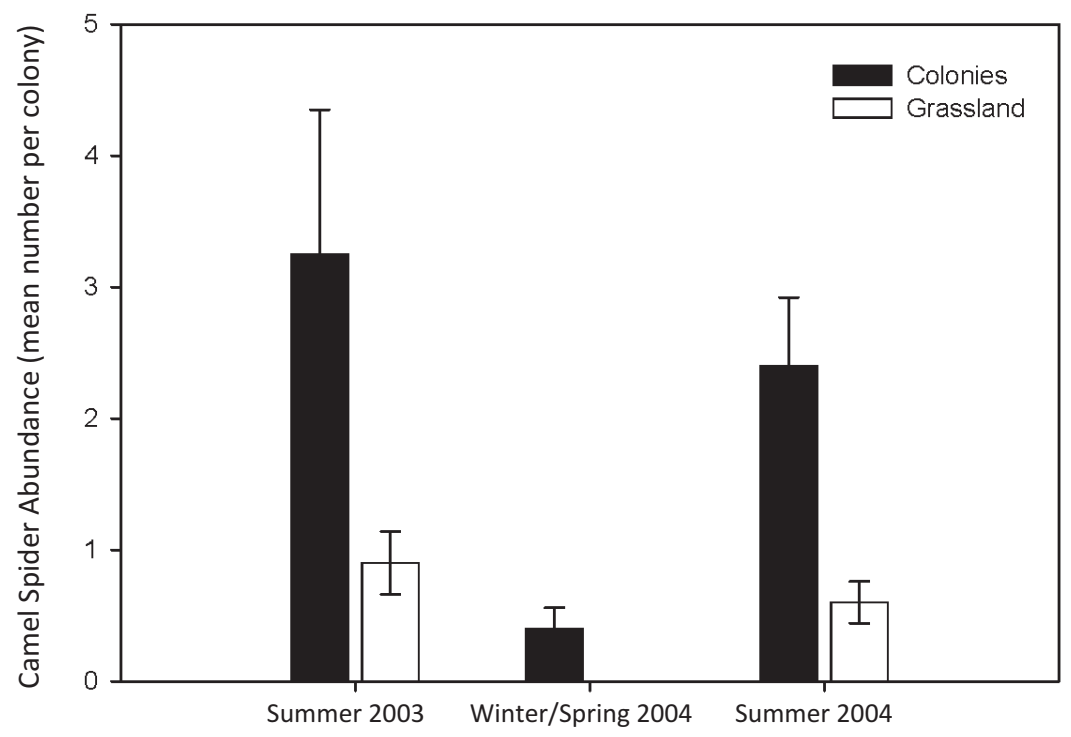

Fig. 2. Abundance of camel spiders on black-tailed prairie dog colonies (black bars) and in adjacent grassland plots (white bars) at the Armendaris Ranch, New Mexico, during summer 2003, winter and spring 2004, and summer 2004. Abundance is presented as mean number of camel spiders collected per sampling date per colony with one standard error. Significantly more camel spiders were collected on colonies for the summer 2003 and summer 2004 sample periods.

Many of the camel spiders we collected were juveniles and difficult to identify. However, we did encounter the following species: Eremobates pallipes, Eremobates similis, Eremochelis bilobatus, and possibly Hemerotrecha fruitana. Species were identified at the Denver Museum of Nature and Science, Denver, Colorado.

Camel spider abundance per trap-week was significantly higher on black-tailed prairie dog colonies $\left(0.47, s_{\bar{x}}=0.09\right)$ than in adjacent grassland $\left(0.12, s_{\bar{x}}=0.02\right)$, (Wilcoxon's rank sum: $t_{\mathrm{s}}$ $=3047.0, P<0.001)$. There was a significant seasonal effect of the abundance of camel spiders, with more specimens collected in summer 2003 and summer 2004 than in winter or spring 2004 (Welch's ANOVA: $F_{2,67.9}=13.15, P<$ $0.001)$. For the summer sampling periods, significantly more camel spiders were collected from colonies than from grassland plots (Welch's ANOVA: summer 2003, $F_{1,20.8}=4.36, P<$ 0.05 ; summer $\left.2004, F_{1,34.1}=10.91, P<0.01\right)$. We collected no camel spiders from the grassland plots during the winter or spring 2004 sample periods, and the only individuals collected for those seasons were found on prairie dog colonies (Fig. 2). While not significant, there was a trend for camel spider abundance to correlate negatively with increased vegetation height (Spearman's rank correlation: $r_{\mathrm{s}}=0.55, P$ $=0.10$ ) and higher basal cover (lower bare ground cover; Spearman's rank correlation: $r_{\mathrm{s}}=$ $0.40, P=0.26)$.

The difference in camel spider abundance between black-tailed prairie dog colonies and adjacent grassland is intriguing given the lack of knowledge of prairie dog effects on arachnids and the paucity of natural history and ecological information about camel spiders. Active, ground-dwelling arthropod predators such as camel spiders are likely sensitive to differences in vegetation structure, and it is therefore intuitive that they would be captured in higher abundance on colonies relative to grassland patches. The increased abundance of camel spiders on colonies adds support to the hypotheses that camel spiders in the Chihuahuan desert prefer open, sandy-soil habitats (Muma 1979, Punzo 1998).

That we found differences in camel spider abundance among seasons highlights 2 important issues. Camel spiders were collected in every season of the study (albeit few in the winter), which suggests that they might be active for most of the year in northern Chihuahuan desert grassland. Also, camel spiders were collected in greater abundance on colonies than at 
adjacent sites for every sampling period. Camel spiders are actively foraging predators, and while their presence on colonies does not necessarily imply that they live on colonies, their presence suggests that they are using colonies in some capacity.

In addition to reducing vegetation cover and increasing bare soil cover, prairie dog burrowing behavior creates a network of deep burrows not found in adjacent grassland (Hoogland 1995). Camel spiders are generally nocturnal and require respite from extreme desert temperatures but are relatively poor at creating their own burrows (Muma 1966b). It is therefore possible that the observation of more camel spiders on prairie dog colonies is related to their use of prairie dog burrows.

Punzo (1998) has stated that a proper treatment of desert arthropod community structure should consider the influence of camel spiders within and on these communities. Although such an analysis is beyond the scope of this report, our results suggest that camel spiders use prairie dog colonies in some capacity, likely because of decreased vegetation height and cover, increased areas of bare ground, and a preponderance of burrows created by prairie dogs. As voracious predators, camel spiders may drastically influence an arthropod community associated with the vegetation-structure differences between colonies and grassland. Other studies have reported lower abundances of grasshoppers and harvester ants on prairie dog colonies (O’Meilia et al. 1982, Kretzer and Cully 2001). More-recent research has demonstrated higher abundances of grasshoppers and general increases in arthropod diversity on colonies (Russell and Detling 2003, Bangert and Slobodchikoff 2006). While beyond the purview of this report, changes in the abundance of predators like camel spiders could be responsible for those patterns. Our data add to the growing evidence that prairie dog colonies support different numbers of important arthropod taxa compared to grassland plots.

Furthermore, because camel spiders are prey items for invertebrates and colony associates like Western Burrowing Owls, prevalence of camel spiders increases at least one prey species on prairie dog colonies (Polis and McCormick 1986, York et al. 2002, Duval unpublished data). By directly modifying the environment, prairie dogs indirectly influence arthropod communities and provide foraging resources by creating favorable habitat patches for camel spiders within the larger grassland mosaic.

We thank W.E. Braswell, D. Richman, and 2 anonymous reviewers for thoughtful comments on earlier drafts of the manuscript. Jon Hernandez assisted with field collections. We sincerely thank Jack Brookhart for identifying specimens. Research funds were provided by grants to W.G. Whitford from the International Arid Lands Consortium and the United States Environmental Protection Agency's Office of Research and Development. We also thank the Jornada Experimental Range, Las Cruces, New Mexico, for support of this research.

\section{Literature Cited}

Agnew, W., D.W. Uresk, and R.M. Hansen. 1986. Flora and fauna associated with prairie dog colonies and adjacent ungrazed mixed-grass prairie in western South Dakota. Journal of Range Management 39: $135-139$.

Bangert, R.K., and C.N. Slobodchikoff. 2006. Prairie dog ecosystem engineering increases arthropod beta and gamma diversity. Journal of Arid Environments 67:100-115.

Broокнавт, J.O. 1972. Solpugids (Arachnida) in Colorado. Southwestern Naturalist 17:31-41.

Daubenmire, R.F. 1968. Plant communities: a textbook on plant synecology. Harper and Row, New York.

Desmond, M.J., J.A. SAVIDGE, AND K.M. Eskridge. 2000. Correlations between Burrowing Owls and blacktailed prairie dog declines: a 7-year analysis. Journal of Wildlife Management 64:1067-1075.

Dick-PedDie, W.A. 1993. New Mexico vegetation: past, present and future. University of New Mexico Press, Albuquerque.

Duval, B.D., E. Jackson, and W.G. Whitford. 2005. Mesquite (Prosopis glandulosa) germination and survival in black-grama (Bouteloua eriopoda) grassland: relations between microsite and heteromyid rodent (Dipodomys spp.) impact. Journal of Arid Environments 62:541-554.

Greenslade, P.J.M. 1964. Pitfall trapping as a method for studying populations of Carabidae (Coleoptera). Journal of Animal Ecology 33:301-310.

HoOGLAND, J.A. 1995. The black-tailed prairie dog: social life of a burrowing animal. University of Chicago Press, Chicago, IL.

Jones, C.G., J.H. LaWTON, AND M. SHachaK. 1994. Organisms and ecosystem engineers. Oikos 69:373-386. 1997. Positive and negative effects of organisms as physical ecosystem engineers. Ecology 78: 1946-1957.

Kretzer, J.E., And J.F. Cully. 2001. Prairie dog effects on harvester ant species diversity and density. Journal of Range Management 54:11-14.

Muma, M.H. 1966a. Feeding behavior of North American Solpugida (Arachnida). Florida Entomologist 49: 199-216. 
1966b. Burrowing habits of North American Solpugida (Arachnida). Psyche 73:251-260.

. 1979. Arid grassland solpugid population variations in southwestern New Mexico. Florida Entomologist 62:320-328.

O’Meilia, M.E., F.L. Knopf, and J.C. Lewis. 1982. Some consequences of competition between prairie dogs (Cynomys ludovicianus) and beef cattle for herbage in Oklahoma pastures. Journal of Range Management 35:580-585.

Polis, G.A., AND S. MCConmick. 1986. Scorpions, spiders and solpugids: predation and competition among distantly related taxa. Oecologia 71:111-116.

Punzo, F. 1998. The biology of camel spiders (Arachnida, Solifugae). Kluwer Academic Publishers, Norwell, MA. 312 pp.

Russell, R.E., and J.K. Detling. 2003. Grasshoppers (Orthoptera: Acrididae) and black-tailed prairie dogs (Sciuridae: Cynomys ludovicianus (Ord)): associations between two rangeland herbivores. Journal of the Kansas Entomological Society 76:578-587.

STAPP, P. 1998. A reevaluation of the role of prairie dogs in Great Plains grasslands. Conservation Biology 12: $1253-1259$
Topping, C.J., and K.D. Sunderland. 1992. Limitations to the use of pitfall traps in ecological studies exemplified by a study of spiders in a field of winter wheat. Journal of Applied Ecology 29:485-491.

Vermeire, L.T., R.K. HeITSChmidt, P.S. Johnson, AND B.F. SOWELL. 2004. The prairie dog story: do we have it right? BioScience 54:689-695.

Weltzin, J.F., S.A. ARcher, and R.K. Hetschmidt. 1997. Small mammal regulation of vegetation structure in a temperate savanna. Ecology 78:751-763.

Whicker, A.D., AND J.K. DetLing. 1988. Ecological consequences of prairie dog disturbances. BioScience 38:778-785.

Whitford, W.G. 1975. Jornada Validation Site Report. US/IBP Desert Biome Research Memorandum 754. Ecology Center, Utah State University, Logan.

York, M.W., D.K. Rosenberg, and K.K. Strum. 2002. Diet and food niche breadth of Burrowing Owls (Athene cunicularia) in the Imperial Valley, California. Western North American Naturalist 62:280-287.

Received 3 October 2007 Accepted 24 September 2008 